\title{
Hawaiian Duck's Future Threatened by Feral Mallards
}

Tearly $70 \%$ of Hawai'i's native
bird species are found
nowhere else on Earth, and many
of these species are declining or in
danger of extinction. Although the
Hawaiian Islands were once home to
a remarkable diversity of waterfowl,
only three species remain-the
Hawaiian Goose (Nēnē), Laysan
Duck, and Hawaiian Duck (Koloa
maoli)-all Federally endangered.
The Koloa maoli is the only Hawaiian
bird threatened by "genetic
extinction" from hybridization with
an invasive species-feral Mallard
ducks. U.S. Geological Survey
(USGS) biologists in Hawai'i are
working to find the causes of bird
endangerment and ways to prevent
extinction of the Koloa maoli and
other threatened birds.

The Federally endangered Hawaiian Duck (Anas wyvilliana) ("Koloa maoli" or simply "Koloa" in Hawaiian), is an endemic species (found nowhere else on Earth) of the Hawaiian Islands. The greatest current threat to the future of the Koloa is cross-breeding or "hybridization" with the introduced Mallard (A. platyrhynchos). The Mallard was brought to Hawai 'i for

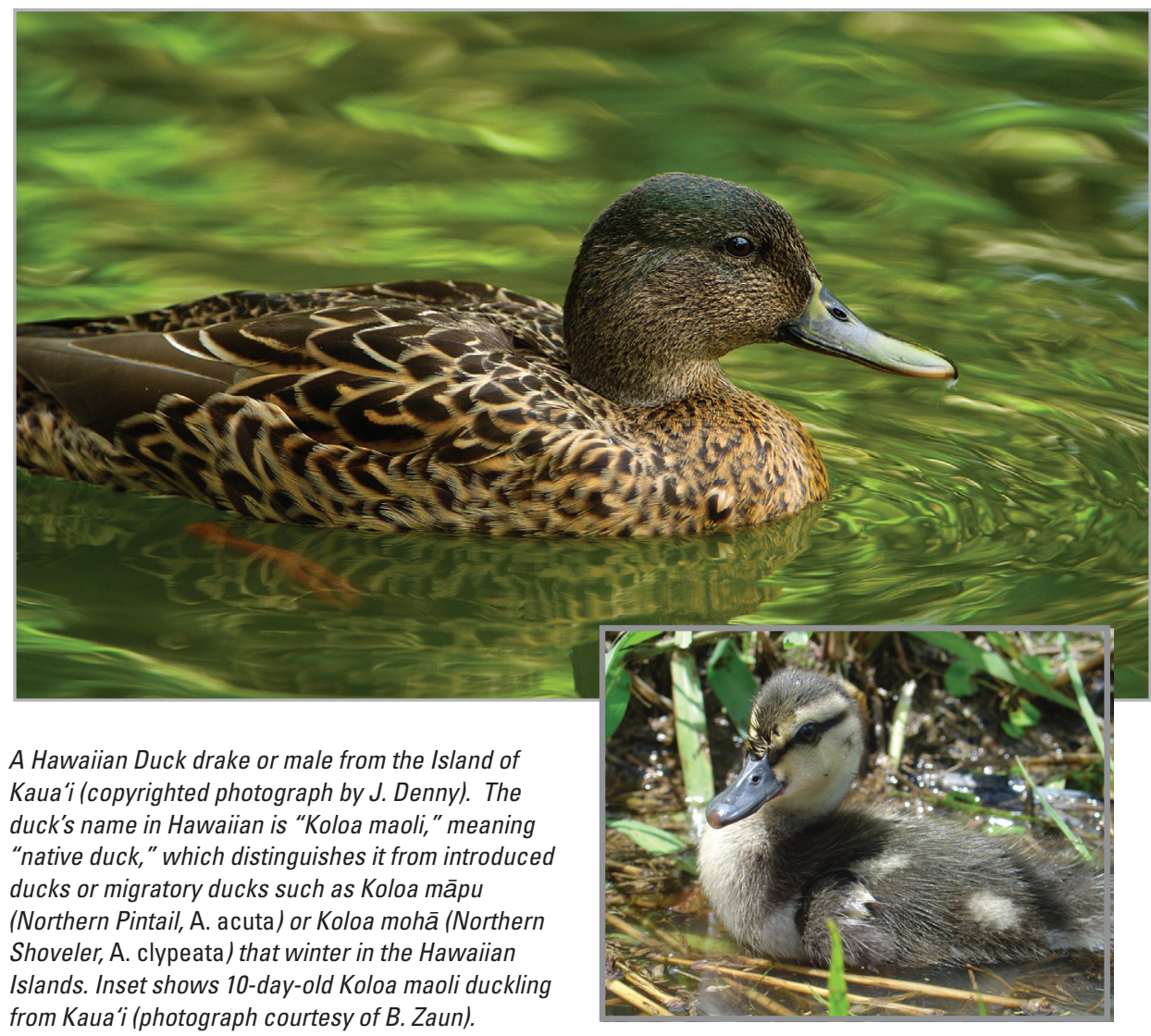

farming, sport hunting, and pond beautification, but it escaped into the wild and became "feral."

Koloa were once common on the main Hawaiian Islands. Until recently, scientists believed that more than 2,000 "true" Koloa remained, primarily on the islands

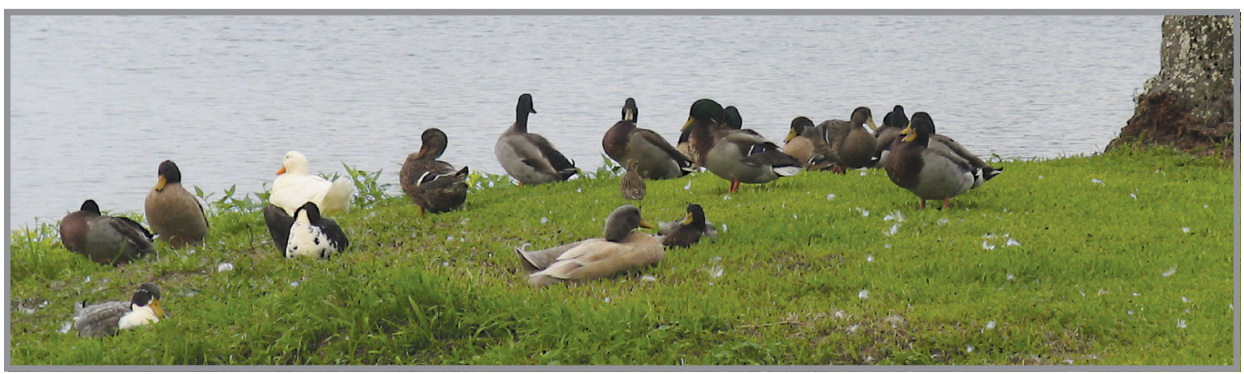

The greatest threat to the future of the Koloa maoli as a unique species is cross-breeding with the introduced Mallard duck (A. platyrhynchos). This photograph shows feral Mallards, including "barnyard ducks," at Wailoa River State Park on Hawai'i. (Photograph by K. Uyehara.)

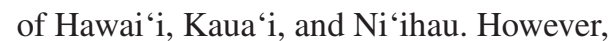
recent evidence shows that even these populations contain Mallard $\times$ Koloa hybrids.

The Koloa is a small dabbling duck similar in appearance to the Mallard but genetically distinct and differing in size, plumage, and behavior. The Koloa is a deeper, richer brown, more secretive, and about 20 to 30\% smaller than the Mallard. The Koloa can be found from sea level to about 10,000 feet elevation in a diversity of wetland habitats. Habitat-use studies reveal that, in addition to lowlands, the Koloa frequents mountain wetlands and skillfully maneuvers winding river corridors and forest canopy, where human activity is minimal. However, little else is known about the breeding ecology, home range, movements, or population dynamics of this endangered duck. 


\section{WHY IS CROSS-BREEDING WITH FERAL MALLARDS THE GREATEST THREAT TO THE FUTURE OF THE KOLOA?}

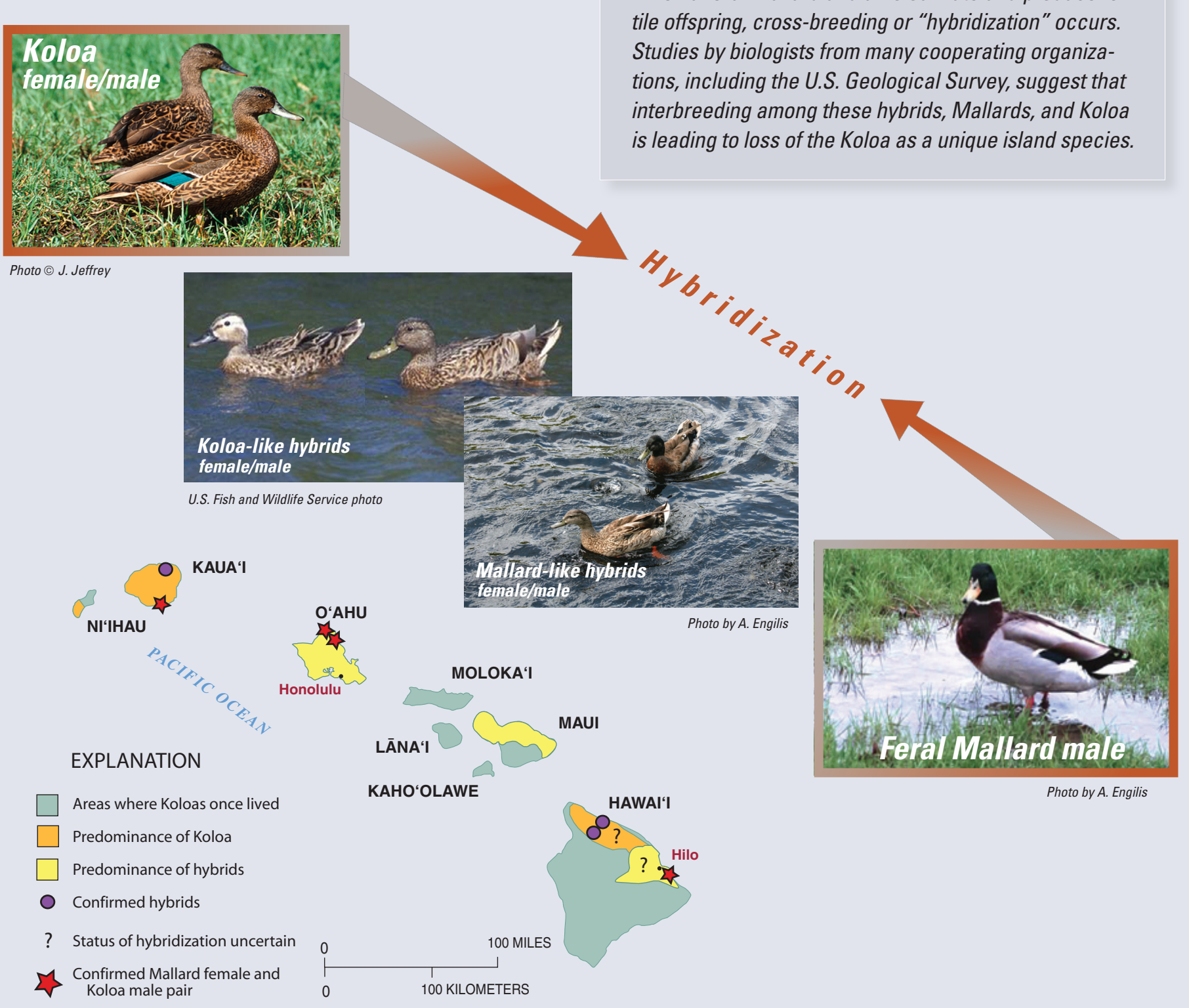

Current distribution of Koloa $\times$ Mallard hybrids on the main Hawaiian Islands (data from Engilis and others, 2002, and U.S. Fish and Wildlife Service).

\section{The Greatest Threats-Introduced Spe- cies and Hybridization}

Introductions of nonnative species can bring species together that were previously geographically isolated and had separate gene pools. This is particularly a problem when "aggressive" introduced species, such as feral Mallards, come in contact with rare native species.

Studies in other parts of the world have shown that feral Mallards are dominant ducks, adapted to survive and reproduce in habitats with human introduced predators. They also are well adapted to using habitats degraded by human activity. These factors may give feral Mallards a competitive edge over native ducks, such as the Koloa.

When a Mallard and Koloa mate, they produce fertile, hybrid offspring. Because of this, interbreeding among hybrids, Mallards, and Koloa can over generations lead to loss of the Koloa as a unique island species.

\section{Mallards in Hawai'i}

Mallard imports to Hawai' $i$ began in the late 1800s for stocking ornamental ponds and farming. In the 1950s and 1960s, hundreds of Mallards were 
imported from North American game farms to stock some hunting areas in the Hawaiian Islands. Unlike "resident" feral Mallards, which are thought to be the descendants of such domestic stock, migratory Mallards that occasionally stop over or winter in the Hawaiian Islands are rare, not in breeding condition, and do not pose a threat to Koloa.

In addition to the "true" Mallard, there are Mallard domestic breeds or "barnyard ducks." They come in various shapes, sizes, and colors and can breed with and are the same species as the Mallard. Common Mallard breeds found in Hawai'i include the Pekin, Khaki Campbell, Blue Cayuga, Rouen, and Indian Runner. Barnyard ducks are bred for characteristics such as egg production or appearance. Although the chances of a Koloa and barnyard duck directly hybridizing in the wild are very small, many scientists have raised concerns about the large numbers of abandoned domestic ducks found on public water bodies and the possibilities that these ducks harbor bird and human diseases.

In the late 1980s, the Mallard was placed on the State of Hawai'i's List of Restricted Animals for importation, which allows exceptions for research and exhibition. In 2002, the Hawai'i Department of Agriculture placed an embargo on all birds shipped to the islands (with some exceptions, for example, fertile eggs) to protect the public from West Nile Virus. However, the Mallard continues to reproduce and be sold in the State.

\section{Resolving the Feral Mallard Dilemma in Hawai'i}

Removing the feral Mallard threat in the Hawaiian Islands is recommended by the U.S. Fish and Wildlife Service's (FWS) draft recovery plan for the Koloa. However, even biologists have trouble distinguishing between Koloa, feral Mallards, and hybrids in the field, because the size and plumage of hybrids can vary greatly. To help with this problem, scientists at the University of California at Davis and the U.S. Geological Survey (USGS) are developing techniques to more accurately differentiate duck types.

\section{Hope for the Future of the Koloa}

Koloa conservation involves not only gathering scientific data but also

\section{THE GLOBAL FERAL MALLARD THREAT}

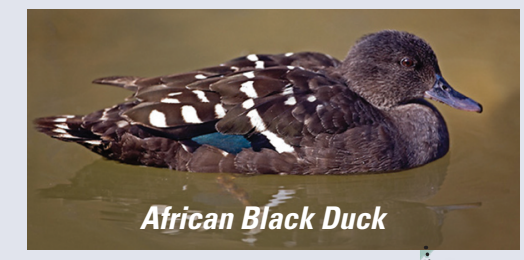

Photo $\odot$ H. Stiver

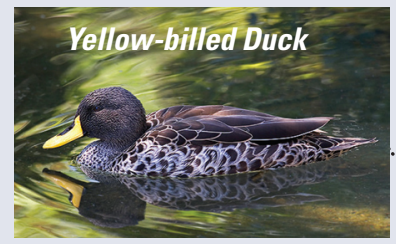

Photo $\odot$ H. Stiver

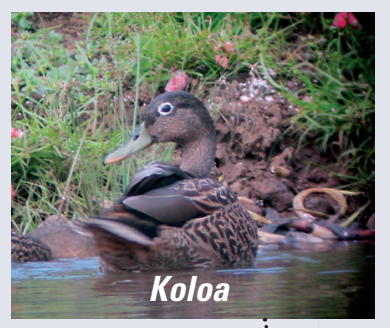

Photo by B. Zaun
Worldwide, native ducks are vulnerable to invasion and hybridization with feral Mallards, particularly when already in jeopardy from habitat loss and introduced mammalian predators. The Mallard occurs naturally in the Northern Hemisphere, but because of its popularity, people have transported it to areas where it was not previously found. Mallard introductions have caused conflicts with native duck populations throughout the world. In New Zealand, descendants of game-farm Mallards, estimated to number 4 to 5 million, are responsible for the near extinction of the New Zealand Grey Duck. In South Africa, Mallards introduced by farmers and waterfowl collectors now threaten both the African Black Duck and Yellow-billed Duck.

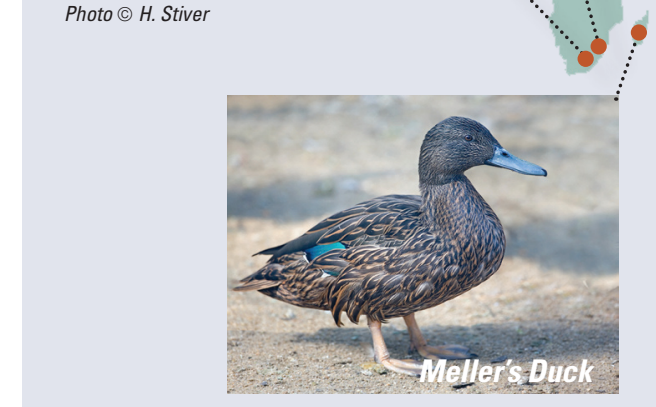

Photo $\odot$ H. Stiver

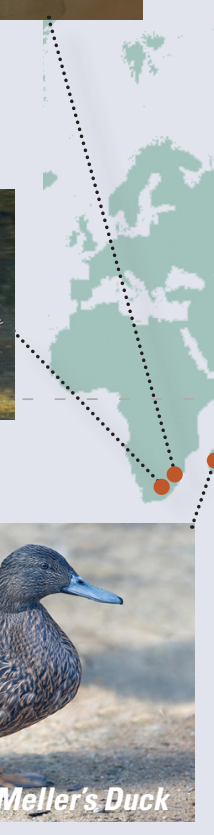
(1)

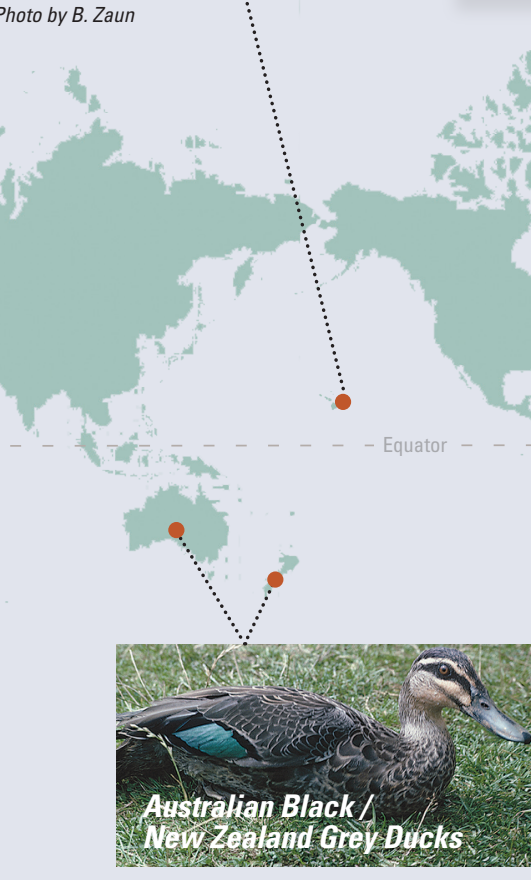

Photo by C.D. Roderick 


\section{WHAT STILL NEEDS TO BE DONE TO ENSURE THE FUTURE OF THE KOLOA?}

Research

- Determine range, behavior, and abundance of Koloa, feral Mallards, and their hybrids in Hawaii.

- Estimate the extent of hybridization between these species.

- Develop practical techniques for differentiating Koloa, Mallards, and their hybrids.

Planning

- Develop a Koloa Conservation Plan to address the feral Mallard problem and use research results to guide management actions.

Recommendations

- Inform the public about the feral Mallard threat to Hawai'i's endemic ducks.

- Ensure new stocks of Mallards and closely related ducks that threaten Koloa are not imported.

- Humanely remove existing feral Mallards and hybrids from the wild and prevent additional releases of captive Mallards.

informing the public and policymakers about the feral Mallard threat and developing humane methods for threat removal. The Koloa is protected by the Federal Endangered Species Act, but Mallard $\times$ Koloa hybrids are not.

Feral duck control programs in other regions have made significant strides toward conserving native duck populations, providing conservation models for Hawai 'i to follow. In Florida, for example, feral Mallards threaten the native Mottled Duck, and the State Fish and Wildlife Conservation Commission prohibits possession of Mallards (with
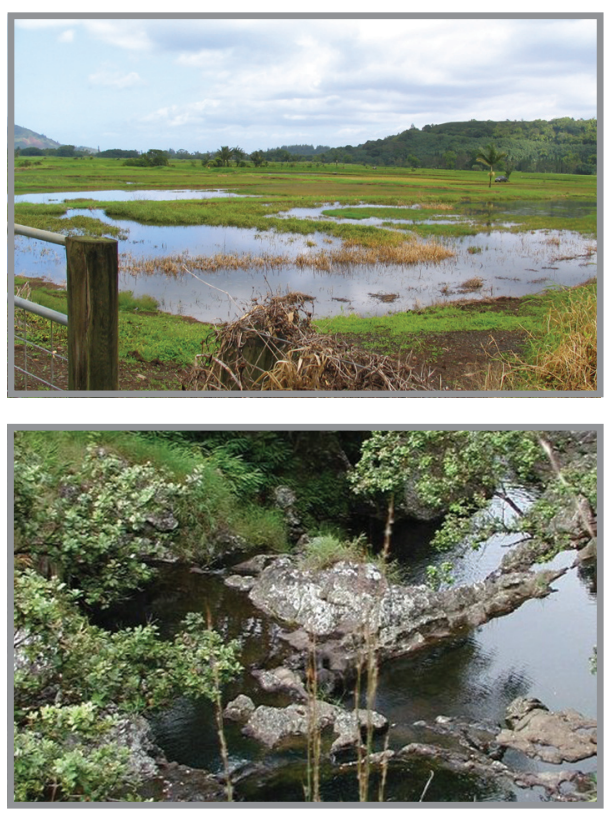

Koloa habitats in lowlands at Hanalei National Wildlife Refuge on Kaua'i (top) and mountain streams in Kohala on Hawai'i (bottom). Because Koloa and Mallards are thought to have similar needs, improvements to these habitats to benefit Koloa would also benefit feral Mallards and their hybrids. (Photographs by K. Uyehara.) exemptions for licensed shooting preserves and dog training), requires proper caging for permitted ducks, and prohibits sale of Mallards to anyone not properly permitted.

Fortunately, once feral Mallards are removed, Hawai 'i's isolated, island environment may provide natural barriers to reinvasion. The FWS describes the Koloa as having "a high potential for recovery." Although little is known about the Koloa, it may be resilient in facing many of the threats that have extinguished other native Hawaiian birds. Given suitable Mallard-free habitat, the Koloa is expected to recover to self-sustainable breeding populations.

\section{WHAT CAN YOU DO TO HELP THE KOLOA?}

- Do not feed or shelter feral Mallard ducks.

- Do not import, buy, or sell Mallards or their eggs.

- Do not release Mallards into the wild. Every Mallard released is a potential threat to Koloa.

- Consider having Mallards removed from your property. Contact the Hawai'i Division of Forestry and Wildlife for advice.

- Be a responsible owner of domestic ducks, such as Pekin or Rouen, by keeping ducks penned, pinioned, or clipped, so that they do not leave your property.

- Share this information with others.

\section{Recommended Reading}

Engilis, A., Jr., and Pratt, T.K., 1993, Status and population trends of Hawaii's native waterbirds, 1977-1987: Wilson Bulletin, v. 105 , p. 142-158.

Engilis, A., Jr., Uyehara, K.J., and Giffin, J.G., 2002, Hawaiian Duck (Anas wyvilliana), in Poole, A., and Gill, F., eds., The birds of North America, No. 694: Philadelphia, The Birds of North America, Inc.

Florida Fish and Wildlife Conservation Commission, 2004, A conservation plan for the Florida Mottled Duck: [http://myfwc.com/ duck/mottled/].

Rhymer, J., and Simberloff, D., 1996, Extinction by hybridization and introgression: Annual Review of Ecology and Systematics, v. 27, p. 83-109.

U.S. Fish and Wildlife Service, 2005, Draft revised recovery plan for Hawaiian waterbirds: [http://www.fws.gov/pacificislands/]. Kimberly J. Uyehara, Andrew Engilis, Jr.,
and Michelle Reynolds

Edited by James W. Hendley II Graphic design by Judy Weathers

\section{COOPERATING ORGANIZATIONS}

Hawai'i Cooperative Studies Unit,

Pacific Aquaculture and Coastal Resources Center, University of Hawai'i at Hilo University of California, Davis

\begin{tabular}{|c|}
\hline For more information contact: \\
Michelle Reynolds \\
U.S. Geological Survey \\
Pacific Island Ecosystems Research Center \\
Kilauea Field Station \\
P.O. Box 44, Bldg. 344 \\
Hawaii National Park, HI, 96718 \\
Email: michelle_reynolds@usgs.gov \\
http://biology.usgs.gov/pierc/ \\
This Fact Sheet and any updates to it are available online at \\
http://pubs.usgs.gov/fs/2007/3047/
\end{tabular}

